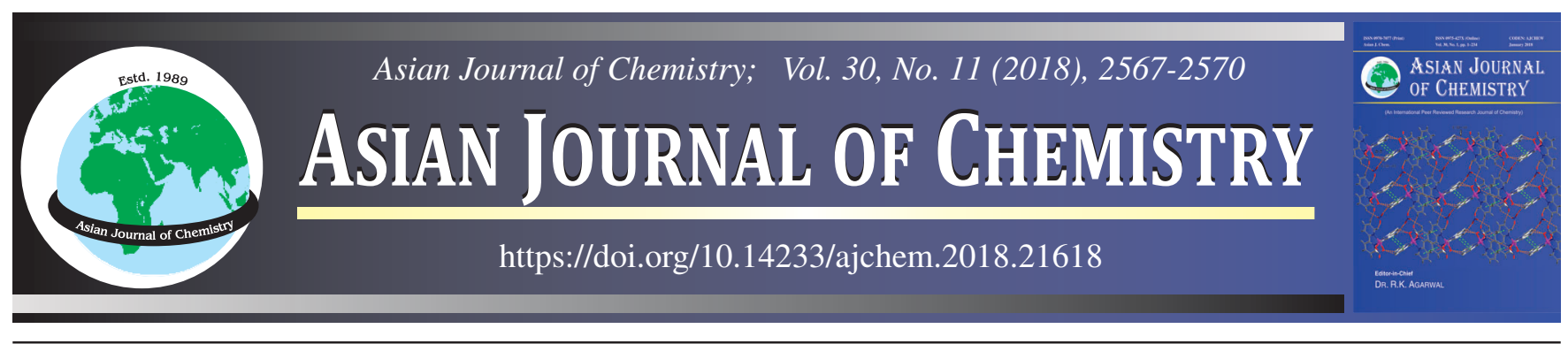

\title{
Quantitative Determination of Dexamethasone in Pharmaceutical Tablets with Continuous Wavelet Transforms
}

\section{S. Dermis, E. Buker*, Z.C. ERTekin, E. KorkmaZ and E. DinC}

Department of Analytical Chemistry, Faculty of Pharmacy, Ankara University, Ankara, Turkey

*Corresponding author: E-mail: eda_buker@yahoo.com

Received: 30 July 2018;

Accepted: 5 September 2018;

Published online: 27 September 2018;

AJC-19112

| The UV absorption spectra were processed by using the continuous wavelet transform for the determination of dexamethasone in tablets In order to get optimal wavelet transform, some wavelet families were tested to transform the UV-absorption spectra of the related drug in the spectral region of $210.0-312.3 \mathrm{~nm}$. In the test procedure of wavelet families, it was observed that Mexican hat function-continuous wavelet transform (mexh-CWT) and Daubechies 8-continuous wavelet transform (db8-CWT) were appropriate for the UV spectra for the | quantitative estimation of dexamethasone. The validity of proposed continuous wavelet transform signal analysis methods were performed by using the analysis results of the solutions for validation samples. In the method validation studies, the percent recoveries and their relative standard deviations were found as $100.7 \%$ and 0.78 for mexh-CWT procedure and $100.2 \%$ and 1.28 for db8-CWT procedure. It was concluded that both mexh-CWT and db8-CWT methods were useful approaches for the determination of dexamethasone in tablets.

Keywords: Continuous wavelet transform, Mexican Hat function, Daubechies 8, Dexamethasone.

L

\section{INTRODUCTION}

Dexamethasone (1) is an artificial derivative of glucocorticoid of steroid drugs that has anti-inflammatory and immunosupressive activities, being used on the treatment of arthritis, asthma, eye inflammations and illness of collagen, as well as on the protection of undesirable immune reaction. Based on the WHO's list of essential medicines, dexamethasone is of the most important medications that has an ancient story of use in a basic health system [1]. It is assigned chemically as an artificial adrenocortical steroid, is a white, odourless, crystalline powder and insoluble in water.

Many analytical methods such as UV-spectrophotometry [2], differential UV spectrophotometry [3] and reverse-phase HPLC [4-6] and TLC $[7,8]$ have been utilized to assay dexamethasone. Spectral analysis of mixtures containing multi-component is one of the main challenges of analytical chemistry. On the other hand, some of the other spectral analysis problems are the correction of spectral baseline and the elimination of noise. In addition, in complex samples the main signal of analyte can interfere with a noise peak.<smiles>CC1CC2C3CCC4=CC(=O)C=CC4(C)C3(F)C(O)CC2(C)C1(O)C(=O)CO</smiles>

Chemical structure of dexamethasone (1), IUPAC: 9-fluoro-11 $\beta, 17,21$ trihydroxy-16 $\alpha$-methylpregna-1,4-diene-3,20-dione; m.f.: $\mathrm{C}_{22} \mathrm{H}_{29} \mathrm{O}_{5} \mathrm{~F}$; m.w. $392.47 \mathrm{~g} / \mathrm{mol}$ )

Various classical graphical and numerical methods have been used to overcome the above analytical drawbacks. In all cases, these classical techniques may not give expected analysis results. However, wavelet transform (WT) is an efficient mathematical tool for the resolution of the above mentioned inconvenient problems. Today, continuous wavelet transforms is one of the most frequently used techniques for the spectral analysis of drugs in commercial pharmaceutical dosage forms [9-11].

This is an open access journal, and articles are distributed under the terms of the Creative Commons Attribution-NonCommercial 4.0 International (CC BY-NC 4.0) License, which allows others to copy and redistribute the material in any medium or format, remix, transform, and build upon the material, as long as appropriate credit is given and the new creations are licensed under the identical terms. 
In this study, a new method based on one dimensional continuous wavelet transform was improved for the spectrophotometric quantitative analysis of dexamethasone in commercial tablets. Various wavelet families were verified to get the ideal wavelet transform of spectra. Then, Mexican hat functioncontinuous wavelet transform (mexh-CWT) and Daubechies 8-continuous wavelet transform (db8-CWT) were studied out to be appropriate for the spectral quantification of the dexamethasone. The use of wavelet transform methods does not require any chemical pre-separation process for compounds in case of interfering spectral bands the related compounds. After validation procedure, mexh-CWT and db8-CWT, signal analysis methods were effectively employed to the analysis of commercial pharmaceutical tablets.

\section{EXPERIMENTAL}

A Shimadzu 1601 double beam spectrophotometer with arranged slit width $(2 \mathrm{~nm})$ linked to a computer filled with Shimadzu UVPC program was utilized to record the zero-order spectra of calibration set, validation and commercial pharmaceutical tablet samples. The spectral data treatments, statistical calculations and spectral transformation procedure were carried out by using an unique algorithm created in Matlab and Microsoft Excel software.

Pharmaceutical tablet formulation: A commercial tablet formulation (produced by Emessa Lab.) contains $0.75 \mathrm{mg} /$ tablet. Active compound, dexamethasone, was received from National Pharm. Industry Firms, Turkey.

Standard solution: Standard stock solution $10 \mathrm{mg} / 100 \mathrm{~mL}$ was prepared by dissolving $10 \mathrm{mg}$ of dexamethasone in $100 \mathrm{~mL}$ calibrated flash with methanol. Calibration solutions of dexamethasone in the concentration range of $5-50 \mu \mathrm{g} / \mathrm{mL}$ were prepared by using the standard stock solution. For validation of method, standard addition samples of dexamethasone in three different concentration levels $5.0,10.0$ and $20.0 \mu \mathrm{g} / \mathrm{mL}$ were prepared from stock solution of dexamethasone.

\section{RESULTS AND DISCUSSION}

In this study, new signal processing methods, continuous wavelet transforms, were applied to the absorption spectra for the analysis of dexamethasone in test samples and tablets. Compared to classical spectrophotometry and derivative spectrophotometry, continuous wavelet transforms provide successful analysis results with higher precision, higher accuracy and high signal-to-noise ratio.

In preliminary experiments, some wavelet families were tested to get optimal transformation of the absorption spectra for giving desirable analysis results. Two families of wavelets, named as Mexican hat function-continuous wavelet transform, (mexh-CWT) and Daubechies 8-continuous wavelet transform (db8-CWT), were found to be appropriate. Fig. 1b-c shows the Mexh-CWT and db8-CWT spectra gained from original absorption spectra of dexamethasone in the working range of $5-50 \mu \mathrm{g} / \mathrm{mL}$.

The absorption spectra of dexamethasone's calibration solutions were noted between 200-320 nm in the concentration range of $5-50 \mu \mathrm{g} / \mathrm{mL}$ (Fig. 1a). In same way, the spectra of validation and commercial samples were plotted. Mexh-CWT
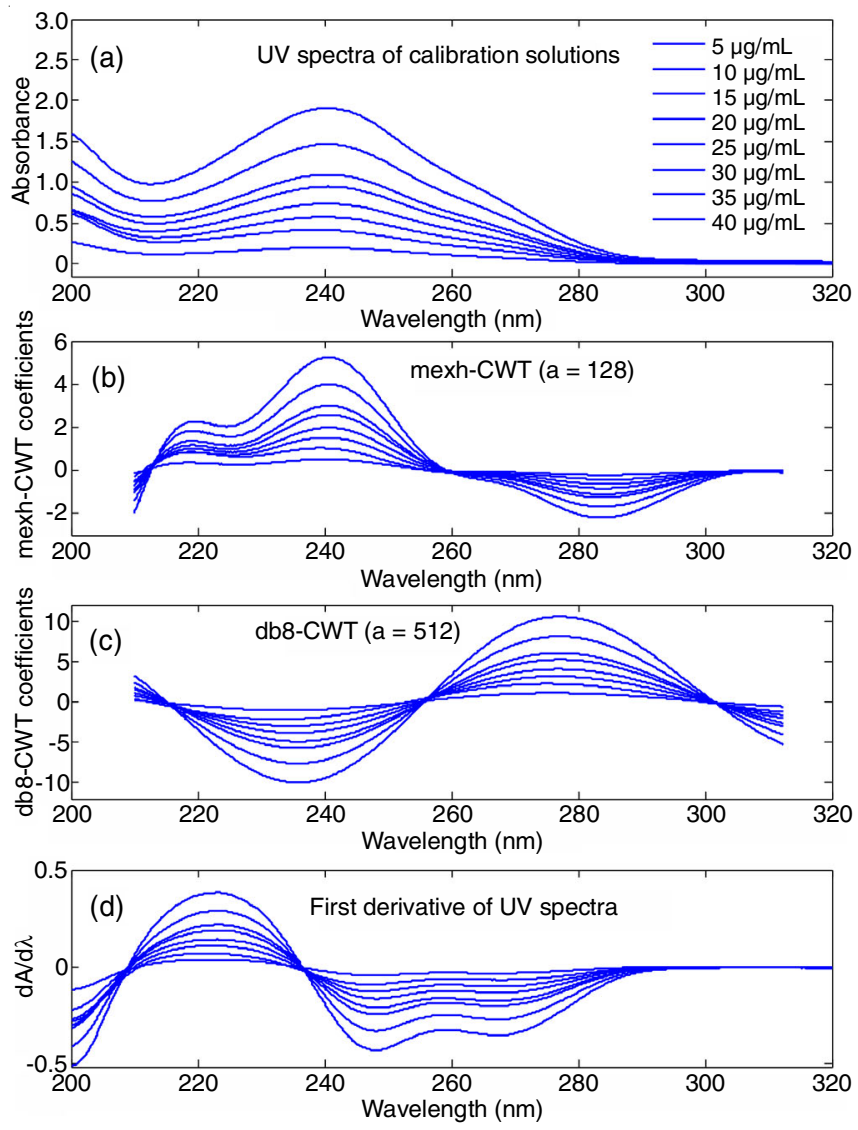

Fig. 2. Zero-order spectra (a), mexh-CWT spectra (b), db8-CWT spectra (c) and first derivative of UV Spectra of dexamethasone in the concentration range of $5.0-50.0 \mu \mathrm{g} / \mathrm{mL}$

and db8-CWT methods were applied for the conversion of the absorption spectra. Linear regression equations were attained by using least squares calculations depending upon the correlation among concentration and wavelet signals at $241.0 \mathrm{~nm}$ for Mexh-CWT and $277.3 \mathrm{~nm}$ for db8-CWT, respectively. Statistical results of least squares calculations were presented in Table-1.

\begin{tabular}{lcccc}
\multicolumn{5}{c}{ TABLE-1 } \\
\multicolumn{5}{c}{$\begin{array}{c}\text { LINEAR REGRESSION ANALYSIS AND } \\
\text { ITS STATISTICAL RESULTS }\end{array}$} \\
\hline \multirow{2}{*}{ Parameter } & $\begin{array}{c}\text { Spectro- } \\
\text { photometry }\end{array}$ & $\begin{array}{c}\text { mexh- } \\
\text { CWT }\end{array}$ & $\begin{array}{c}\text { db8- } \\
\text { CWT }\end{array}$ & DS1 \\
\hline$\lambda(\mathrm{nm})$ & 240 & 241 & 277.3 & 245 \\
$\mathrm{~m}$ & 0.03692 & 0.1032 & 0.2055 & 0.0081 \\
$\mathrm{n}$ & 0.01451 & -0.0341 & 0.0363 & 0.0026 \\
$\mathrm{r}$ & 0.9989 & 0.9995 & 0.9992 & 0.9990 \\
$\mathrm{SD}(\mathrm{r})$ & $2.76 \times 10^{-2}$ & $7.14 \times 10^{-2}$ & $1.51 \times 10^{-1}$ & $6.00 \times 10^{-3}$ \\
$\mathrm{SD}(\mathrm{m})$ & $6.86 \times 10^{-4}$ & $1.77 \times 10^{-3}$ & $3.76 \times 10^{-3}$ & $1.49 \times 10^{-4}$ \\
$\mathrm{SD}(\mathrm{n})$ & $1.81 \times 10^{-2}$ & $5.01 \times 10^{-2}$ & $1.06 \times 10^{-1}$ & $4.20 \times 10^{-3}$ \\
LOD & 1.38 & 1.07 & 1.06 & 1.47 \\
LOQ & 4.89 & 3.85 & 4.16 & 5.21 \\
\hline
\end{tabular}

$\mathrm{m}=$ Slope of the linear regression equation; $\mathrm{n}=$ Intercept of the linear regression equation; $r=$ Correlation coefficient of the linear regression equation; SD $(\mathrm{m})=$ Standard deviation of slope; SD $(\mathrm{n})=$ Standard deviation of intercept; $\mathrm{SD}(\mathrm{r})=$ Standard deviation of correlation; $\mathrm{LOD}$ $=$ Limit of detection $(\mu \mathrm{g} / \mathrm{mL}) ; \mathrm{LOQ}=$ Limit of quantitation $(\mu \mathrm{g} / \mathrm{mL})$

For a comparison, classical spectrophotometry and first derivative spectrophotometry were subjected to the determi- 


\begin{tabular}{|c|c|c|c|c|c|c|c|c|c|}
\hline \multicolumn{10}{|c|}{$\begin{array}{c}\text { TABLE-2 } \\
\text { ANALYSIS RESULTS OF STANDARD ADDITION SAMPLES }\end{array}$} \\
\hline & & \multicolumn{2}{|c|}{ Spectrophotometry } & \multicolumn{2}{|c|}{ mexh-CWT } & \multicolumn{2}{|c|}{ db8-CWT } & \multicolumn{2}{|c|}{ DS1 } \\
\hline Exp & $\begin{array}{c}\text { Added } \\
(\mu \mathrm{g} / \mathrm{mL})\end{array}$ & $\begin{array}{c}\text { Found } \\
(\mu \mathrm{g} / \mathrm{mL})\end{array}$ & $\begin{array}{l}\text { Recovery } \\
(\%)\end{array}$ & $\begin{array}{c}\text { Found } \\
(\mu \mathrm{g} / \mathrm{mL})\end{array}$ & $\begin{array}{l}\text { Recovery } \\
(\%)\end{array}$ & $\begin{array}{c}\text { Found } \\
(\mu \mathrm{g} / \mathrm{mL})\end{array}$ & $\begin{array}{l}\text { Recovery } \\
(\%)\end{array}$ & $\begin{array}{c}\text { Found } \\
(\mu \mathrm{g} / \mathrm{mL})\end{array}$ & $\begin{array}{l}\text { Recovery } \\
(\%)\end{array}$ \\
\hline 1 & 5 & 5.1 & 102.0 & 5.05 & 101.0 & 4.94 & 98.8 & 4.94 & 98.8 \\
\hline 2 & 10 & 9.7 & 97.0 & 10.04 & 100.4 & 10.12 & 101.2 & 10.34 & 103.4 \\
\hline \multirow[t]{4}{*}{3} & 20 & 19.47 & 97.4 & 20.11 & 100.6 & 19.89 & 99.5 & 19.8 & 99.0 \\
\hline & & Mean & 98.8 & & 100.7 & & 99.8 & & 100.4 \\
\hline & & SD & 2.79 & & 0.31 & & 1.24 & & 2.60 \\
\hline & & RSD & 2.83 & & 0.31 & & 1.24 & & 2.59 \\
\hline
\end{tabular}

TABLE-3

ANALYSIS RESULTS OF TEST SAMPLES

\begin{tabular}{|c|c|c|c|c|c|c|c|c|c|}
\hline \multirow[b]{2}{*}{ Exp } & \multirow[b]{2}{*}{$\begin{array}{c}\text { Added } \\
(\mu \mathrm{g} / \mathrm{mL})\end{array}$} & \multicolumn{2}{|c|}{ Spectrophotometry } & \multicolumn{2}{|c|}{ mexh-CWT } & \multicolumn{2}{|c|}{ db8-CWT } & \multicolumn{2}{|c|}{ DS1 } \\
\hline & & $\begin{array}{c}\text { Found } \\
(\mu \mathrm{g} / \mathrm{mL})\end{array}$ & $\begin{array}{c}\text { Recovery } \\
(\%)\end{array}$ & $\begin{array}{l}\text { Found } \\
(\mu \mathrm{g} / \mathrm{mL})\end{array}$ & $\begin{array}{c}\text { Recovery } \\
(\%)\end{array}$ & $\begin{array}{c}\text { Found } \\
(\mu \mathrm{g} / \mathrm{mL})\end{array}$ & $\begin{array}{c}\text { Recovery } \\
(\%)\end{array}$ & $\begin{array}{l}\text { Found } \\
(\mu \mathrm{g} / \mathrm{mL})\end{array}$ & $\begin{array}{c}\text { Recovery } \\
(\%)\end{array}$ \\
\hline 1 & 5 & 5.02 & 97.4 & 4.98 & 99.6 & 5.04 & 100.8 & 5.29 & 105.7 \\
\hline 2 & 15 & 15.07 & 100.4 & 15.08 & 100.5 & 15.06 & 100.4 & 15.53 & 103.5 \\
\hline 3 & 25 & 25.2 & 100.8 & 25.36 & 101.4 & 25.25 & 101.0 & 25.13 & 100.5 \\
\hline 4 & 40 & 39.14 & 96.8 & 39.19 & 98.0 & 40.34 & 100.9 & 39.15 & 97.9 \\
\hline \multirow[t]{4}{*}{5} & 50 & 51.08 & 102.2 & 50.07 & 100.1 & 48.95 & 97.9 & 51.1 & 102.2 \\
\hline & & Mean & 99.5 & & 99.9 & & 100.2 & & 102 \\
\hline & & $\mathrm{SD}$ & 2.32 & & 1.29 & & 1.30 & & 2.98 \\
\hline & & RSD & 2.33 & & 1.29 & & 1.30 & & 2.92 \\
\hline
\end{tabular}

nation of dexamethasone in test samples and tablets. In Table-1, the statistical analysis and results for calibration equations based on the absorbance measurements at $240.0 \mathrm{~nm}$ and $\mathrm{dA} / \mathrm{d} \lambda$ measurements at $245 \mathrm{~nm}$ was listed for classical spectrophotometry and first derivative spectrophotometry (DS1). First derivative of the absorption spectra of dexamethasone in the concentration range $5-50 \mu \mathrm{g} / \mathrm{mL}$ was obtained by using an interval of $\Delta \lambda=8 \mathrm{~nm}$ with smoothing function, in the wavelength region of 200-320 nm. Fig. 1d indicates the first derivative spectra of dexamethasone.

This calibration curves were used for the quantification of dexamethasone in validation samples and commercial tablets. In the validation of the proposed Mexh-CWT and db8-CWT, artificial test samples and standard addition samples were analyzed and then recovery results with standard deviations and relative standard deviations are given in Table-2. Results indicated that both methods gave successful results. Similarly, the results obtained by applying classical spectrophotometry and first derivative spectrophotometry are presented. When the methods were compared to each other, wavelet signal processing methods (Mexh-CWT and db8-CWT) were more precise and accurate than classical spectrophotometry and first derivative spectrophotometry (Tables 2 and 3 ). After validating procedures, all of the proposed methods were applied to analyze the quantity of dexamethasone in commercial samples. Quantitative determination results of dexamethasone in tablet are presented in Table-4.

\section{Conclusion}

In this study, new analytical methods, Mexican hat functioncontinuous wavelet transform (mexh-CWT) and Daubechies 8-continuous wavelet transform (db8-CWT), were utilized to the quantification of dexamethasone in validation samples and pharmaceutical tablet formulation without any effect of excipients on the analysis of active compound. The results provided

\begin{tabular}{|c|c|c|c|c|}
\hline \multicolumn{5}{|c|}{$\begin{array}{c}\text { TABLE-4 } \\
\text { ANALYSIS RESULTS OF COMMERCIAL TABLET }\end{array}$} \\
\hline \multirow[b]{2}{*}{ Exp } & \multicolumn{3}{|c|}{$\mathrm{mg} /$ tablet } & \multirow[b]{2}{*}{ DS1 } \\
\hline & $\begin{array}{c}\text { Zero }= \\
\text { order spect }\end{array}$ & $\begin{array}{l}\text { mexh- } \\
\text { CWT }\end{array}$ & db8-CWT & \\
\hline 1 & 14.98 & 15.09 & 15.07 & 15.14 \\
\hline 2 & 14.57 & 14.96 & 15.10 & 14.67 \\
\hline 3 & 14.94 & 15.18 & 14.94 & 15.13 \\
\hline 4 & 14.70 & 14.90 & 14.73 & 14.77 \\
\hline 5 & 15.27 & 15.55 & 15.34 & 15.54 \\
\hline Mean & 14.89 & 15.14 & 15.04 & 15.05 \\
\hline SD & 0.27 & 0.26 & 0.22 & 0.35 \\
\hline RSD & 1.82 & 1.70 & 1.48 & 2.30 \\
\hline
\end{tabular}

by applying mexh-CWT and db8-CWT methods were compared with those obtained by classical spectrophotometry and first derivative spectrophotometry. It was observed that standard deviations and relative standard deviation for mexh-CWT and db8-CWT were lower than that of zero-order and first-order derivative spectrophotometric methods. This indicated that wavelet signal processing methods were more precise and more accurate than conventional methods. It was concluded that mexhCWT and db8-CWT methods were very suitable for the quality control and quantitative analysis of pharmaceutical tablet formulation containing dexamethasone.

\section{CONFLICT OF INTEREST}

The authors declare that there is no conflict of interests regarding the publication of this article.

\section{REFERENCES}

1. World Health Organization, WHO Model List of Essential Medicines, World Health Organization (2013).

2. M. Chen, X. Zhang, Q. Shao and L. Gan, Yaowu Fenxi Zazhi, 11, 103 (1991).

3. M. Xi, Y. Yang, Q. Shao and Y. Peng, Yaowu Fenxi Zazhi, 11, 291 (1991). 
4. X. Yao and Z. Qiao, Yiao. Gongye, 19, 172 (1988).

5. D. Gagne and B.A. Lodge, J. Chromatogr. A, 193, 160 (1980); https://doi.org/10.1016/S0021-9673(00)81459-4.

6. V.D. Gupta, J. Pharm. Sci., 68, 926 (1979); https://doi.org/10.1002/jps.2600680743.

7. K. Datta and S.K. Das, J. Planar Chromatogr Mod. TLC, 6, 204 (1993).

8. B. Das, S.K. Chatterjee and S.K. Das, J. Liq. Chromatogr., 9, 3461 (1986); https://doi.org/10.1080/01483918608077796.
9. I. Daubechies, Ten Lectures on Wavelets, Society for Industrial and Applied Mathematics, Philadelphia, PA, USA (1992).

10. B. Walczak, Wavelets in Chemistry, Elsevier Press: Amsterdam, The Netherlands. vol. 22, pp. 241-261 (2000).

11. E. Dinç and D. Baleanu, eds.: K. Tas, J.A. Tenreiro Machado and D. Balanu, Mathematical Methods in Engineering, Springer, pp. 265-285 (2007). 